\title{
Dialysis Yi nationality Epic Xianji of A-xi
}

\author{
Na Zhao \\ School of Foreign Languages of Kunming University, Kunming, 650000, China
}

Keywords: Xianji of A-xi, Philosophical ideas.

\begin{abstract}
Xianji of A-xi is an epic A-xi branch of Yi nationality. Circulating in the Western Hills of Maitreya County, Yunnan province. content of this poem is very wide, vividly reflects life of the A'xi people in each stage of primitive society to class society in different aspects, myth intertwined with reality, ideal fused with reality, it is literature and history. This paper based on Xianji of A-xi,analyse philosophical ideas with the content of epic.
\end{abstract}

\section{Introduction}

Epics are early human spirit product, most of them are narrative poem the heroic deeds or historical time.Xianji of A-xi is a epic poem generated orally among A-xi people of Yi minority, telling origins and early life of A-xi, filled with miraculous. "Xianji” means "song”'in A-xi language, later transferred into name of a tune, so call Xianji tune. Whole started with "introduction"and finished with " epilogue"to form rhyme. Content is made up by two main parts "the earliest time" and " persuade male and female into a family"

\section{Research status of Xianji of A-xi}

Xianji of A-xi is one of four epic of Yi nationality, its literary value has attracted the attention of the world for a long time, and many scholars have made a thorough study of its literary value.For example,the Literary Culture of the Yi Nationality that introduced Yi nationality literary history,the book conduct analysis towards artistic evaluation, aesthetic evaluation and historical significance of the Xianji of A-xi. Through research of Yi literary history, Xianji of A-xi analyse contents like mankind origin, sun, start, plant growing and hunting, stated the analysis and opinions towards everything and human society $\mathrm{n}$ a earliest stage of a nationality, reflects the initial research starting point of the development of philosophy.

\section{Philosophical Interpretation of the Yi nationality epic Xianji of A-xi}

Philosophy is the study of the origin, existence and value of some problems. In the philosophical study of minority culture, found two different perspectives: (1) philosophy is an understanding of human understanding of things, but has not all philosophical significance of minority. Philosophy is a scientific and objective analysis of the existence of things and truth. It is an understanding of concepts. It is not a judgment made by man, nor a judgment of what is right or wrong. The rational knowledge that human beings produce after their own independent thinking is the analysis of philosophy. (2) in general, there are national communities with historical deeds and traces of war, and they have their own philosophies. For example, almost all ethnic minorities in China have their own philosophical ideas that reflect the characteristics of the nation. Scholars study the epic through the view of the existence of the nation.

\section{Origin and nature of material}

From the past to the present, the question of the origin of matter has been puzzling people, which has prompted many scholars to think and study it. From the theology of "God created all things", the philosophical view of the later "the universe is born", and the view that "the world is material", is put 
forward in Marx's philosophy...... The human mind is constantly improving, and the fine people are guessing and answering the most profound philosophy. In ancient times, the lack of productivity and science and technology are developed, people can not explain everything in the world is how to exist, so there is a fear of the spirit of this magical phenomenon, a fine race of people and other ethnic groups are interesting and meaning of romantic guess on this magical world they think, "Qi" is the origin of everything. "Qi" is originated from the study of the philosophical connotation of Chuang-tzu. Chuang-tzu thought that "Qi" is an irreplaceable function in the course of the origin and development of matter. Therefore, A-xi people thought that everything in heaven and earth are created by a magic theory. In addition to the analysis of "Qi", we can derive the "wind" which is the beginning of all things, and all things are brought by "wind". Xianji of A-xi descriptive "the capable wind, put the mountain together, being non piece of soil together, place these nine piece stones together, once the mountain is well sited, then the earth will have dragon liked mountains" "Bring those good seeds down to the earth, ....sew them down to the ground, sew it over the mountain, sew them where the sun shine." These description reflects the attention of the people to the wind. They believe that the role of the wind and the sun can promote the growth of all things, and they can produce everything through the wind

\section{Manual labour create everything}

Almost all epic writing has a common theme:manual labor. Minority people believe that the only way of creation of the world and family business is through continuous labor and a firm willpower. In primitive times, A-xi people gain housing or product, tools or food from their own hard work,due to low production capacity is low, people can only explain how to participate in the creative process orally, for other things and curious thoughts that cannot explain, and they will explain it through some powerful man with their own imagination, they created all things through labor.

A-xi people attached great importance to labour. After the formation of heaven and earth, mankind has sown the crops with the seeds of nature, and the wind and the wind bring the rain, so that the seeds germinate and harvest. Slowly, people have the concept of time, the sun is the day, and the moon is the night, so it is a day. Only by distinguishing time can we master the laws of nature, so that we can sow crops according to the laws. Then a fine people found that bees not only clever and industrious, know when to offer later crops, older people warned young people to work hard like bees to rely on harvest to maintain life. 。

\section{Everything originated in the material}

In ancient China, the study of the origin of all things, that all the origin of the "five elements", gold, wood, water, fire and soil evolved. But because of the development of cultural age restrictions, all they think only when they think that the things above, for example, Xianji of A-xi discussed the nature of the world, only the earth, the sun and the moon, vegetation, animal and human origin, there are three kinds of points to heaven and earth, the sun and the moon plant animal and human

In the past, people thought that the world of the moon and the sun contained the celestial bodies such as the world, the sun and the moon, as well as the actual mountain and sea, and that the existence of heaven and earth as well as the mountain and sea was created by the movement of objects. In Xianji of A-xi the origin of the animal and plant has two parts, one is formed at the beginning of the universe, people have experienced many difficulties and hardships,begging for seeds in the south gate; the second is after floods, humankind excitement, the grasshopper straight eyes son and daughter got flowers seeds and animals from the melon. Therefore, it is known that plants have growth laws, and plants and animals are derived from material.

In the primitive populace's psychology, oneself and the nature are a whole, they also continuously distinguish into animal and the plant. As for man from nature,in Xianji of A-xi the origin of human beings is two kinds: (1) human beings originated from "earth".God and goddess create men and women from mud, so they thought that man was from material. (2) human origins in "melon"'. The boy and girl get married in crick age, they plant melon seeds in the ground the melon, and get melon, 
each petal of melon looks like a human organ, then people will think that the birth of human beings from the melon, melon is a carrier, and then affirmed the origin of mankind.

\section{Human life can not be separated from material}

Human beings depend on the existence of natural substances to maintain their daily production and activity needs. A-xi people solved the problem of their food and clothing through labour production and relied on material to improve their life.

Xianji of A-xi mentioned that god and goddess created man and human,being people food and necessary for leaving, A-xi people live on gathering wild fruit and draw, use the bark to make clothes and live in books in order to avoid the attack of wild animals. The early life of the fine man depended on the nature to survive. Slowly A'xi people through the natural products to improve their lives, "melon is the ridge can be used to make smoke pot mouth,A-gaiduo from the wasteland can be used as tobacco rod,ah,..... If you do not eat, you must eat three pots." This is a disruption of how A-xi people smoke Xianji of A-xi, which also describe how A-xi people gather and use material from nature, so until now this form of smoking still exists.

In the primitive society, the production level is too low, the explain of origin of all things on earth are relying on imagination, A-xi people created many myths and legends in life, but no matter how magical plot blurred, have shown the importance of material existence. A fine crop of people to sustain life, a preliminary understanding of the basic things, the emergence of the universe and the nature of things also have a new understanding, gradually aware of the role and importance of matter o

\section{Bisexual conception}

The mankind creation parts in Xianji of A-xi "if man wan to be created,mountains have to be divided into male and female....no male and female, no man can be made"which means must divided into male and female, then man can be generated.By matching objects, nature can distinguish between sexes. Therefore, the fine people believe that everything between heaven and earth is divided into two sexes, and the dialectic of this contradiction has been gradually unified, and this concept of male and female has been extended to this day. Take human sex as an example, but in epic, human beings appear much later than natural things. Therefore, only by distinguishing natural things from men and women, can man distinguish between men and women, and human beings can reproduce

Many mythological gods are in gender roles, the creation of the world, the female worm Pangu created man and so on...... According to the human gender stereotypes of men and women, a fine people will be "God" the gender distinction, a fine man because of poor conditions at that time can not distinguish from natural things, by God's hand to imitate the human world, the God of sexual distinction. Throughout the epic, the idea of both sexes, whether natural beings, man of God, or man, has detailed sexual attitudes. This shows that only when the two sexes promote each other can new things be produced, and then the progress and development of society can be promoted.

\section{Nature will affect life}

Cannot do without the human nature, a fine primitive Betta productivity are backward, Kaoshanchishan by water draft, Du Yu some natural phenomenon can not be explained, but they are on these natural phenomena can affect the life of a certain understanding. Nature has a devastating effect on man's climate and natural disasters, "the ant, the blind generation."...... They all died of the sun." "The buffalo meets the goat."...... Together they burned". Due to climate change "ants blind" this generation of extinction and natural disasters brought disaster, are the ancient times in that period to crowning calamity, human production down must carry out agricultural production, farming food, so at that time is in the process of production with natural disasters can not be avoided 。

\section{The relationship between man and nature}

Xianji of A-xi believed that the origin of all things comes from nature, and vividly shows that people at that time thought they were the products of nature, or that they had a special relationship with nature. This speculation is a conception of human nature, contains the philosophy behind, but with the continuous development of society, people began to pay attention to a fine relationship with 
nature development, and through many efforts to adjust the relationship between human and nature, the skill will slowly anthropology in harmony with nature. But the relationship between man and nature does not exist forever, but rather by slowly adjusting the state of being with nature. Although the beginning A'xi people cannot explain the natural objects and natural phenomena, slowly reversing thinking about the nature of the relationship, with the progress of the times and increase the level of human knowledge, people gradually know how to avoid in nature, human beings and nature can live in harmony.

\section{Conclusion}

Xianji of A-xi themed by people,reflect the significance of philosophy,from how do people live and producing, it has great meaning on extending life way of A-xi and protecting human culture.As China's minority a brilliant masterpiece,Xianji of A-xi will be a more eye-catching attention attitude attracted the eye of the world, in the future in their own unique art popular.

\section{References}

[1] Qiu di. Philosophy of Xianji of A-xi, South-Central University For Nationalities, 2014.

[2] Shi Rongrong. National literature heritage of Yi minority, Shaanxi Normal University, 2011.

[3] Yang Minyue. A preliminary study of the Creation Epic "Xianji of A-xi, Journal of the Central Institute for nationalities, 1986, (04): 87-90.

[4] Li Ming.Discussion on Yi's epic Xianji of A-xi, Journal of Southwest Nationalities Institute (PHILOSOPHY AND SOCIAL SCIENCE EDITION), 1981, (02): 84-93. 